\title{
The Contribution of Neuromuscular Stimulation in Elucidating Muscle Plasticity Revisited
}

\author{
Dirk Pette (1), Gerta Vrbová (2) \\ (1) Department of Biology, University of Konstanz, Konstanz, Germany; (2) Department of \\ Anatomy and Developmental Biology, University College London, London, UK \\ This article is distributed under the terms of the Creative Commons Attribution Noncommercial License (CC BY-NC 4.0) which permits
} any noncommercial use, distribution, and reproduction in any medium, provided the original author(s) and source are credited.

\begin{abstract}
Studies carried out during the past 45 years on the effects of chronic low-frequency stimulation on skeletal muscle have revealed a multiplicity of adaptive changes of muscle fibres in response to increased activity. As reflected by induced changes in the metabolic properties, protein profiles of the contractile machinery and elements of the $\mathrm{Ca}^{2+}$-regulatory system, all essential components of the muscle fibre undergo pronounced changes in their properties that ultimately lead to their reversible transformation from fast-to-slow phenotype. The chronic low-frequency stimulation experiment thus allows exploring many aspects of the plasticity of mammalian skeletal muscle. Moreover it offers the possibility of elucidating molecular mechanisms that remodel phenotypic properties of a differentiated post-mitotic cell during adaptation to altered functional demands. The understanding of the adaptive potential of muscle can be taken advantage of for repairing muscle damage in various muscle diseases. In addition it can be used to prevent muscle wasting during inactivity and aging. Indeed, pioneering studies are still the sound grounds for the many current applications of Functional Electrical Stimulation and for the related research activities that are still proposed and funded. Key Words: $\mathrm{Ca}^{2+}$ regulatory proteins, electrical stimulation, energy metabolism, muscle fiber transformation, myofibrillar proteins
\end{abstract}

Eur J Transl Myol 2017;27(1):33-39

The present paper is not a comprehensive review but it was written to illustrate findings that show the dynamic state of skeletal muscle fibers. Early studies on rabbit soleus muscle had shown that the maintenance of phenotypic properties depended on activity. ${ }^{1}$ Further development of this observation lead to experiments that used externally applied electrical stimulation. ${ }^{1,2}$ The application of this technique provided an opportunity to study the phenotypic adaptability of the terminally differentiated muscle fibre. The purpose of this article is not to provide a review of all the observations made since but rather to show the evolution of ideas that have contributed to the notion of muscle plasticity.

The term plasticity of muscle has been coined during the preparation of an international symposium held at the University of Konstanz in September 1979. ${ }^{3}$ The topics that were treated included the heterogeneity of muscle as a tissue, the programme of its ontogeny and differentiation, and the regulation of its properties by innervation, use, hormones and modulation of neural input. The state of the art on these subjects was such that the time was ripe to bring together scientists from various disciplines to discuss these issues.
It has been known for a long time that mammalian muscle fibres are not all the same but differ in their various properties. ${ }^{4-6}$ The problem of understanding the significance of this diversity for the organization of motor control had been highlighted in the last century by studies of Henneman and his colleagues who discovered that motoneurones supplying particular types of muscle fibres are specialized. ${ }^{7}$ Those motoneurones that supply slow and fatigue resistant muscle fibres have a lower threshold and are more active, whereas motoneurones to muscle fibres that contract and relax fast have a high threshold and are therefore less active. The relationship between the motoneurone and muscle fibres it supplies was most clearly illustrated by Eccles and co-workers in the early 60th by their cross reinnervation experiments. ${ }^{8}$ The mechanism as to how motoneurones control muscle properties was not clear at that time but has been attributed to a special trophic influence of the motor nerve on muscle. An alternative proposal that could explain these observations, was that re-innervating the muscle with an alien nerve, had altered its activity pattern. This interpretation was supported by tenotomy experiments on rabbit soleus 
muscle which changed the activity pattern of the muscle without altering its innervation. Returning the continuous activity of the soleus nerve to the silenced tenotomised muscle by electrical stimulation restored the slow time course of contraction. ${ }^{1}$ It was concluded from these experiments that the continuous impulse activity normally present in postural soleus muscle, is responsible for the slow time course of contraction and relaxation of this muscle.

Due to the initiative of Ernest Gutmann and Sidney Hilton, Gerta and Dirk met at this stage, and decided to join forces to elucidate this programme. Their encounter and collaboration turned out to be chance and necessity. The data reported here is mainly derived from that collaboration and should not be considered a comprehensive review as most of this has been covered by several reviews. ${ }^{9-11}$

Earlier studies on energy metabolism in functionally distinct muscles had led to the definition of specific and constant proportions in the enzyme activity patterns. These findings supported the notion that energy supply is adjusted to specific functional demands of different muscles. ${ }^{12}$ The analysis of enzyme activity patterns, therefore, represented an appropriate tool to investigate metabolic specialization of muscles and other tissues. ${ }^{13}$

The application of this approach to cross re-innervated muscles in rabbit showed pronounced changes in the enzyme patterns matching the induced functional changes. ${ }^{14}$ Similar metabolic changes were described in cross re-innervated muscles of cat and rat. ${ }^{15-17}$ Nevertheless, it was clear that these experiments did not provide an answer that distinguished between the hypotheses of trophic factors or activity regulating muscle properties.

The development of new implantable materials then allowed examining the hypothesis that activity is responsible for determining muscle properties by means of the chronic stimulation experiment. Electrodes were implanted either side of the peroneal nerve in one leg of anesthetized rabbits. The electrodes were then connected to a stimulating device and impulses of supramaximal intensity at $10 \mathrm{~Hz}$ were delivered to the nerve. This frequency pattern resembled that of motoneurones innervating the soleus muscle. This did not cause discomfort to the animal. Contractile properties of the stimulated tibialis anterior (TA) and extensor digitorum longus (EDL) muscles were examined at various time intervals using conventional physiological methods. Within two to four weeks, the stimulated muscle became more slowly contracting. ${ }^{1,2}$ At this stage Gerta and Dirk started their collaboration and together they examined enzyme profiles of stimulated and control muscles. In these studies, a profound re-arrangement of enzyme activity and isozyme patterns confirmed that prolonged slow frequency $(10 \mathrm{~Hz})$ activity imposed on fast muscles that were normally getting their energy from breakdown of glycolytic pathways, induced their transformation towards a slow-oxidative muscle.

At that time, the interpretation of our results was not readily accepted by the scientific community that favoured the idea of trophic factors released from the nerve being responsible for determining muscle properties ${ }^{8}$ Even at that time this view was challenged by A.F. Huxley who suggested that the slow frequency activity of slow motoneurones induces a vibratory stress to fast muscles that elicits the change from fast to slow phenotype (l.c. Buller et al. 1960). ${ }^{8}$

The dramatic transformation of adult differentiated fast glycolytic muscle fibres into slow oxidative ones by altered activity inspired us to use this experimental model to study not only the potential of this tissue to adjust to activity but also to unravel the mechanisms by which such changes are induced.

\section{Chronic low-frequency stimulation as an experimental model}

In addition to establishing the physiological importance of activity as a decisive factor in determining muscle properties, chronic nerve stimulation of fast muscle at low frequency provided an excellent model for studying the time course of activity-induced changes. In other words, the stimulation experiment allowed us to follow changes of cellular re-organization in a differentiated post-mitotic tissue during its transition from a relatively stable to an altered state induced by new functional demands. It also enabled us to investigate both, the hierarchy and the sequence of changes at different levels of cellular organization and, establish the full range of adaptation during the transition from a fast to a slow muscle, and finally propose a mechanism that initiated this change.

Another advantage of the stimulation experiment was that all motor units of the target muscle were simultaneously activated by the same pattern of activity. The unstimulated contralateral muscles served as an intra-animal control. Systemic influences such as stress, changes in hormone homeostasis, etc., would thus equally affect stimulated and contralateral control muscles. Analyses of time-dependent changes of chronic low-frequency stimulation (CLFS), demanded standardization of the experimental set-up so as to create reproducible conditions regarding patterns, intensity and duration of activity transmitted to the target muscle. This was achieved by developing a method of tele-stimulation. ${ }^{18}$

In the following text, effects of CLFS on selected properties of muscle fibres in response to this new type of activity are described. Apart from functional tests, our studies included energy metabolism, contractile and regulatory proteins of the myofibrillar apparatus and the sarcoplasmic reticulum. These objects were chosen in the hope to elucidate both the hierarchy and sequence of changes that would help to explain the mechanisms underlying the adaptive potential of the muscle. 


\section{Metabolic transformation}

The metabolic transformation of rabbit fast-twitch muscles (EDL, TA) exposed to low-frequency stimulation (CLFS) was characterized by increases of enzyme activities involved in aerobic-oxidative metabolism and simultaneous decreases in glycogenolytic and glycolytic metabolic capacities. ${ }^{19-23}$ Twenty eight days after the onset of stimulation glycogenolytic and glycolytic capacities decreased to $\sim 40 \%$ of their control values, while there was an almost 8 -fold increase in mitochondrial volume density. The relative activities of soluble and membrane-bound enzymes of aerobic oxidative metabolism (the citric acid cycle, fatty acid oxidation) remained unaltered although their absolute activity levels increased by 5-8fold. $^{22}$

An even greater increase was seen in B-hydroxybutyrate dehydrogenase, a structure-bound mitochondrial enzyme. In contrast, glycerolphosphate oxidase, another mitochondrial structure-bound enzyme representing the mitochondrial part of the glycerolphosphate shuttle, markedly decreased and paralleled the changes in glycolytic capacity. These results taken together, suggest that not only was there an increase in mitochondria but also a change of their composition.

Stimulation of fast muscles also induced an early and pronounced increase in capillary density. ${ }^{24}$ The study of the time course of this increase compared to that of succinate dehydrogenase (a marker for mitochondria) revealed that the change in capillary density preceded that in aerobic-oxidative capacity. ${ }^{25}$ An improved oxygen supply provided by the capillaries thus might have induced the increase in mitochondria.

\section{Contractile proteins}

The altered time course of contraction after CLFS had indicated a change in the contractile machinery of the muscle. This was confirmed by qualitative histochemistry of myofibrillar ATPase activity. Stimulated muscles displayed a greater proportion of fibres histochemically classified as slow (type I). ${ }^{20,21,26}$ Subsequent studies showed alterations in the composition of myofibrillar proteins in whole muscle and in single fibre extracts. The myosin isoform patterns, both at the levels of light (MLC) and heavy (MHC) chains were shifted towards slower isoforms. The time course of these changes in rabbit muscle suggested a sequential exchange of fast with slow isoforms in the order of MHCIId, MHCIIa, MHCI. This sequence was confirmed in single fibre studies that also showed appearance of hybrid fibre types co-expressing several MLC and MHC isoforms. ${ }^{27,28}$ Expression patterns of MHC isoforms, both at the levels of mRNA and protein in single fibres at different stages of transformation displayed a greater variability at the mRNA than that at the protein level. ${ }^{28}$ The coexistence of different mRNA isoforms in the same fibre was not always seen at the protein level, indicating that the switch from transcription to translation is likely to be separately controlled.

Studies of the time course of MHC isoform transitions performed on rat muscle provided similar results. However in rats, the fastest fibres in EDL and TA muscles are type IIB which contain MHCIIb. ${ }^{29}$ When exposed to CLFS, these fibres are first transformed into type IID and successively type IIA. Considering the results from both, rat and rabbit muscle, the fast-to-slow transition isoforms occurs in an orderly manner so that MHCIIb -> MHCIId -> MHCIIa -> MHCI.

During these fibre transitions, isoforms initially present in the fibre were replaced by newly synthesised isoforms which resulted in the transitory appearance of hybrid fibres containing more than one MHC isoform. As documented by single fibre analysis, the complete sequence of fast-to-slow transitions was as follows:

MHCIIb -> MHCIIb/IId -> MHCIId -> MHCIId/IIa -> MHCIIa -> MHCIIa/I -> MHCI.

Depending on the initial phenotype of the fibre, the CLFS-induced fast-to-slow transitions differ between fibres. This has been revealed by single fibre analyses. ${ }^{30}$ These changes are reversible as most CLFS-induced changes studied so far. The direction of the arrows in the above scheme can be reversed. Therefore, discontinuing stimulation presents the possibility for the study of slow-to-fast transitions. ${ }^{31-33}$

As illustrated in studies on rat muscle, the initial change of the transformation consisted of a repression of MHCIIb. Its decay was faster at the mRNA than at the protein level. The corresponding half-lives amounted to approximately 3 days for the mRNA and $11 \mathrm{~d}$ for the protein which indicated a rapid re-modelling of the myofibrillar apparatus in response to increased activity. ${ }^{33}$ Newly synthetized MHCIId and MHCIIa replacing MHCIIb, were traced in rat TA muscle by measuring protein synthesis by ${ }^{35} \mathrm{~S}$-methionine incorporation. Increases in synthesis of MHCIId and MHCIIa occurred as soon as two days after stimulation onset. ${ }^{34}$ This data supported our notion that changes in MHC isoform expression are early processes in response to the altered activity

\section{$\mathrm{Ca}^{2+}$-regulatory proteins}

Fast-to-slow transformation included also exchanges of fast with slow isoforms of the regulatory proteins at the level of the thin filament. Due to the greater number of isoforms, especially in the case of troponin with three fast and two slow isoforms, the fast-to-slow transitions proved to be more complex. Nevertheless, the time course studies showed that the shift from fast to slow occurred in a manner coordinated with that of the MHC isoforms. ${ }^{35}$

The major changes in the protein profile of the sarcoplasmic reticulum (SR) consisted of an exchange of the fast SERCA1 with the slow SERCA2 $\mathrm{Ca}^{2+}$ ATPase isoform. This exchange paralleled the fast-toslow transition at the stage from MHCIIa to MHCI. ${ }^{36}$ 
The switch in SERCA isoforms was preceded by a partial (40-50\%) inactivation of the ATPase activity ${ }^{37-39}$ due to protein oxidation and nitration of tyrosyl groups of the enzyme. ${ }^{40}$ Both processes may contribute to the prolonged relaxation in the stimulated muscle. In addition to these alterations of $\mathrm{Ca}^{2+}$-ATPase, other proteins were also affected. These included pronounced decreases $(\sim 60 \%)$ in the levels of ryanodine receptor, dihydropyridine receptor, sarcalumenin, and triadin. Calsequestrin displayed only a small decrease of $\sim 20 \%$. $^{36}$

Parvalbumin, a cytosolic $\mathrm{Ca}^{2+}$-binding protein present only in fast-twitch fibres, was decreased rapidly during CLFS. Its decay in rabbit muscle paralleled the first step (MHCIId to MHCIIa) of the fast-to-slow transition in MHC isoforms. ${ }^{41}$ Loss of parvalbumin may, therefore, explain the early changes in relaxation speed.

These early changes of proteins involved in $\mathrm{Ca}^{2+}$-uptake indicated alterations in intracellular $\mathrm{Ca}^{2+}$-dynamics. These changes might induce alterations in gene expression related to $\mathrm{Ca}^{2+}$-dependent signalling. Indeed, measurements of $\mathrm{Ca}^{2+}$ transients in single fibres isolated from rat EDL muscle exposed to CLFS showed an instantaneous $\sim 2.5$-fold increase in resting $\mathrm{Ca}^{2+}$ which was maintained during the entire period of 10 days of stimulation. ${ }^{42}$ This value was in the range characteristic of slow-twitch fibres from soleus muscle. There was also a transitory increase of the integral $\mathrm{Ca}^{2+}$ per pulse with a maximum ( $\sim$-fold) after 1 day. Steep decreases in the rate constant of $\mathrm{Ca}^{2+}$-decay could be explained by an immediate impairment of the $\mathrm{Ca}^{2+}$-uptake and by an additional loss of $\mathrm{Ca}^{2+}$-binding capacity, most likely due to the decay in parvalbumin.

It has been shown that the expression of specific protein patterns in distinct muscle fibre types is under the control of $\mathrm{Ca}^{2+}$-dependent signalling. Sustained increases of resting $\mathrm{Ca}^{2+}$ levels have been shown to activate transcription of slow fibre-specific proteins mediated by a calcineurin-dependent pathway. ${ }^{43}$ An impairment of $\mathrm{Ca}^{2+}$-uptake in the stimulated muscle by the early partial inactivation of the SR $\mathrm{Ca}^{2+}$-ATPase, and the decrease in cytosolic $\mathrm{Ca}^{2+}$-binding capacity (parvalbumin) are likely to be responsible for the increased levels of resting $\mathrm{Ca}^{2+}$ and the activation of molecules controlling the slow phenotype.

The impairment of $\mathrm{Ca}^{2+}$-uptake that preceded the SERCA1 to SERCA2 transition, may, however, not only result from the above mentioned mechanisms but may also be due to a compromised energy state of the stimulated muscle fibre. In fact, measurements of the ATP phosphorylation potential $\left[\mathrm{ATP} / \mathrm{ADP}_{\text {free }}\right]$ in whole muscle and single fibres revealed an almost instantaneous drop after stimulation onset. ${ }^{28,44}$ The ATP phosphorylation potential remained for up to 50 days of stimulation at $\sim 50 \%$ of that in unstimulated muscle. The drop in the phosphorylation potential was accompanied by an almost instantaneous decrease in force production which was reduced to $28 \%$ of the control immediately after the onset of stimulation and gradually recovered during the following 10 days. ${ }^{44,45}$ The recovery of force was most likely brought about by the metabolic transformation, i.e. the improved energy supply via aerobic-oxidative pathways.

Consistent with this is the finding that lowering the cellular phosphorylation potential by other means, such as by administration of a creatine analogue, has also been shown to shift myosin isoform expression towards the slow phenotype, but these changes were less complete than those brought about by CLFS. ${ }^{46,47}$ The instantaneous effects of CLFS thus affect at least two major elementary functions of the muscle fibre, its energy state and its $\mathrm{Ca}^{2+}$ homeostasis. These may be the initial signals effecting signalling pathways controlling the expression of phenotypic properties in various compartments of the muscle fibre.

In summary, these and other results of the multiple effects of CLFS demonstrate the value of this experimental set-up for studying muscle plasticity and its regulatory mechanisms. In our opinion, this model has not been fully exploited and offers unique possibilities for studies of regulatory processes underlying muscle plasticity. Such studies need a multidisciplinary approach as shown in the present report.

\section{Application of electrical stimulation to treatment of neuromuscular disorders}

Results of experiments on mutant mice suffering from severe muscle weakness (C7BL dy/2J/dy2J), show that a particular pattern of activity imposed upon their muscles by stimulation of their nerve reduces the rate of deterioration of their muscles. These mutant mice have a defect of laminin alpha 2 (Lama 2) gene. ${ }^{48}$ CLFS of their leg muscles lead to a reduction of the rate of loss of force and muscle bulk that is typical in these animals. ${ }^{49,50}$ Moreover, CLFS reversed the changes in enzyme activities caused by the disease in these dystrophic mice. ${ }^{51}$

The encouraging results obtained on animal models led to attempts to investigate the effects of CLFS in patients suffering from Duchenne muscular dystrophy. Consistent with the results on mice, the results showed that electrical stimulation reduces the rate of deterioration of ankle dorsi-flexors and quadriceps muscles, provided the stimulation was started before the muscles became excessively weak. The frequency at which the muscles were stimulated was of critical importance for only stimulation at $10 \mathrm{~Hz}$ or less had a beneficial effect, while frequencies of $30 \mathrm{~Hz}$ or more enhanced the deterioration of the muscles. ${ }^{52,53}$

With the development of methods that attempt treatment of muscle diseases by trying to correct the genetic fault by exon skipping (Duchenne muscular dystrophy) or by interfering with the splicing mechanism of the cell by antisense oligonucleotides (SMA) it may be beneficial to induce prior to treatment a situation where the 
affected muscle is already undergoing changes in gene expression by CLFS-induced alterations in transcriptional and/or epigenetic regulation.

Finally, other effects of electrical stimulation such as increases of capillary density and blood flow, may allow better access of any substance to target muscles. An additional change contributing to an altered responsiveness of the muscle, might relate to the increase in satellite cell activation under influence of low-frequency stimulation. ${ }^{54}$

These few suggestions point out the possibilities of using stimulation induced changes either on their own or in combination with other therapeutic interventions for treatment of neuromuscular disorders. It is surprising that these approaches have so far not been used, particularly in view of extensive evidence that electrical stimulation of human muscle is efficient as judged by biochemical and functional criteria, ${ }^{55}$ and has recently been so widely and successfully used for rehabilitation of various conditions. ${ }^{56}$ These include procedures used for the maintenance of muscle function after spinal cord injury, ${ }^{57}$ denervation, ${ }^{58}$ and aging. ${ }^{59,60}$ These important results also provided evidence that in human muscles electrical stimulation was able to reverse many of the degenerative changes that follow denervation. ${ }^{58,61}$ As a consequence of these beneficial effects patients were able to use their muscles during locomotion and counteract the effects of aging and long term inactivity.

\section{Author's contributions}

Authors equally organized the draft and wrote the typescript.

\section{Acknowledgments}

We wish to thank our colleagues who helped to develop the work reported in this paper over many years. We are also grateful for the financial support given to us by various grant giving organisations in particular the Deutsche Forschungsgemeinschaft, the Medical Research Council UK, the Muscular Dystrophy Group UK.

\section{Conflict of Interest}

The authors declare no conflict of interests.

\section{Corresponding Authors}

Dr. Dirk Pette, Department of Biology, University of Konstanz, D-78457 Konstanz, Germany

E-mail: dirk.pette@uni-konstanz.de

Dr. Gerta Vrbová, Division of Biosciences, Faculty of Live Sciences, Gower Str. WC1E 6BT London UK E-mail: g.vrbová@ucl.ac.uk

\section{References}

1. Vrbová G. The effect of motoneurone activity on the speed of contraction of striated muscle. J Physiol 1963;169:513-26.
2. Salmons S, Vrbová G. The influence of activity on some contractile characteristics of mammalian fast and slow muscles. J Physiol 1965;201:535-49.

3. Pette D. Plasticity of Muscle. Berlin New York: de Gruyter; 1980.

4. Pette D, Staron RS. Cellular and molecular diversities of mammalian skeletal muscle fibers. Rev Physiol Biochem Pharmacol 1990;116:1-76.

5. Canepari M, Pellegrino MA, d'Antona G, Bottinelli R. Review: skeletal muscle fiber diversity and the underlying mechanisms. Acta Physiol 2010;199:465-76.

6. Schiaffino S, Reggiani C. Fiber types in skeletal muscles. Physiol Rev 2011;91:1447-531.

7. Henneman E, Clamann HP, Gilllies JD, Skinner RD. Rank order of motoneurones within a pool: law of combination. J Neurophysiol 1974;37:133849.

8. Buller AJ, Eccles JC, Eccles RM. Interactions between motoneurones and muscles in respect of the characteristic speeds of their responses. J Physiol.1960;150:417-30.

9. Pette D, Vrbová G. Invited review: neural control of phenotypic expression in mammalian muscle fibers. Muscle Nerve 1985;8:676-89.

10. Pette D, Vrbová G. Adaptations of mammalian muscle fibers to chronic electrical stimulation. Rev Physiol Biochem Pharmacol 1992;120:116-202.

11. Pette D, Vrbová G. Invited review: What does chronic electrical stimulation teach us about muscle plasticity? Muscle Nerve 1999;22:666-77.

12. Pette D, Bücher T. Proportionskonstante Gruppen in Beziehung zur Differenzierung der Enzymaktivitätsmuster von Skelett-Muskeln des Kaninchens. Hoppe-Seyler's Z Physiol Chem 1963;331:180-95.

13. Pette D. Plan und Muster im zellulären Stoffwechsel. Naturwiss 1965;52:597-616.

14. Golisch G, Pette D, Pichlmaier H. Metabolic differentiation of rabbit skeletal muscle as induced by specific innervation. Eur $\mathrm{J}$ Biochem 1970;6:110-6.

15. Drahota Z, Gutmann E. Long-term regulatory influence of the nervous system on some metabolic differences in muscles of different function. Physiol Bohemoslov 1963;12:330-48.

16. Dubowitz V, Newman DL. Changes in enzyme pattern after cross-innervation of fast and slow skeletal muscle. Nature 1967;214:840-1.

17. Prewitt MA, Salafsky B. Enzymic and histochemical changes in fast and slow muscles after cross-innervation. Am J. Physiol 1979;218:69-74.

18. Schwarz G, Leisner E, Pette D. Two telestimulation systems for chronic indirect muscle stimulation in caged rabbits and mice. Pflügers Arch 1983;398:130-3. 
19. Pette D, Smith ME, Staudte HW, Vrbová G. Effects of long-term electrical stimulation on some contractile and metabolic characteristics of fast rabbit muscles. Pflügers Arch 1973;338:257-72.

20. Pette D, Ramirez BU, Müller W, Simon R, et al. Influence of intermittent long-term stimulation on contractile, histochemical and metabolic properties of fibre populations in fast and slow rabbit muscles. Pflügers Arch 1975;361:1-7.

21. Pette D, Müller W, Leisner E, Vrbová G. Time dependent effects on contractile properties, fibre population, myosin light chains and enzymes of energy metabolism in intermittently and continuously stimulated fast twitch muscle of the rabbit. Pflügers Arch 1976;364:103-12.

22. Reichmann H, Hoppeler H, Mathieu-Costello O, et al. Biochemical and ultrastructural changes of skeletal muscle mitochondria after chronic electrical stimulation in rabbits. Pflügers Arch 1985;404:1-9.

23. Hood DA, Pette D. Chronic long-term stimulation creates a unique metabolic enzyme profile in rabbit fast-twitch muscle. FEBS Lett 1989;247:471-4.

24. Cotter M, Hudlicka O, Vrbová G. Growth of capillaries during long-term activity in skeletal muscle. Bibl Anat 1973;11:395-8.

25. Skorjanc D, Jaschinski F, Heine G, Pette D. Sequential increases in capillarization and mitochondrial enzymes in low-frequencystimulated rabbit muscle. Am J Physiol 1998;274:C810-8.

26. Sréter FA, Gergely J, Salmons S, Romanul F. Synthesis by fast muscle of myosin light chains characteristic of slow muscles in response to longterm stimulation. Nature New Biol 1973;241:17-9.

27. Staron RS, Gohlsch B, Pette D. Myosin polymorphism in single fibers of chronically stimulated rabbit fast-twitch muscle. Pflügers Arch 1987;408:444-50.

28. Conjard A, Peuker H, Pette D. Energy state and myosin heavy chain isoforms in single fibers of normal and transforming rabbit muscles. Pflügers Arch 1998;436:962-9.

29. Aigner S, Gohlsch B, Hämäläinen N, et al. Fast myosin heavy chain diversity in skeletal muscles of the rabbit: heavy chain IId, and not IIb predominates. Eur J Biochem 1993;211:367-72.

30. Pette D, Staron RS. Mammalian skeletal muscle fiber type transitions. Int Rev Cytol 1997;170:143223.

31. Eisenberg BR, Brown JM, Salmons S. Restoration of fast muscle characteristics following cessation of chronic stimulation. Ultrastructure of slow-tofast transformation. Cell Tissue Res 1984;238:22130 .

32. Kirschbaum BJ, Schneider S, Izumo S, et al. Rapid and reversible changes in myosin heavy chain expression in response to increased neuromuscular activity of rat fast-twitch muscle. FEBS Lett 1990;268:75-8.

33. Jaschinski F, Schuler M, Peuker H, et al. Changes in myosin heavy chain mRNA and protein isoforms of rat muscle during forced contractile activity. Am J Physiol 1998;274:C365-70.

34. Termin A, Pette D. Changes in myosin heavychain isoform synthesis of chronically stimulated rat fast-twitch muscle. Eur $\mathrm{J}$ Biochem 1992;204:569-73.

35. Leeuw T, Pette D. Coordinate changes in the expression of troponin subunit and myosin heavychain isoforms during fast-to-slow transition of low-frequency-stimulated rabbit muscle. Eur J Biochem 1993;213:1039-46.

36. Ohlendieck K, Frömmig GR, Murray BE, et al. Effects of chronic low-frequency stimulation on $\mathrm{Ca}^{2+}$-regulatory membrane proteins in rabbit fast muscle. Pflügers Arch 1999;438:700-8.

37. Leberer E, Härtner KT, Pette D. Reversible inhibition of sarcoplasmic reticulum Ca-ATPase by altered neuromuscular activity in rabbit fasttwitch muscle. Eur J Biochem 1987;162:555-61.

38. Dux L, Green HJ, Pette D. Chronic low-frequency stimulation of rabbit fast-twitch muscle induces partial inactivation of the sarcoplasmic reticulum $\mathrm{Ca}^{2+}$-ATPase and changes in its tryptic cleavage. Eur J Biochem 1992;192:95-100.

39. Matsushita $\mathrm{S}$, Pette $\mathrm{D}$. Inactivation of sarcoplasmic-reticulum $\mathrm{Ca}^{2+}$-ATPase in lowfrequency-stimulated muscle results from a modification of the active site. Biochem $\mathbf{J}$ 1992;285:303-9.

40. Klebl B, Ayoub AT, Pette D. Protein oxidation, tyrosine nitration, and inactivation of sarcoplasmic reticulum $\mathrm{Ca}^{2+}$-ATPase in low-frequency stimulated rabbit muscle. FEBS Lett 1998;422:381-4.

41. Huber B, Pette D. Dynamics of parvalbumin expression in low-frequency stimulated fast-twitch rat muscle. Eur J Biochem 1996;236:814-9.

42. Carrol S, Nicotera P, Pette D. Calcium transients in single fibers of low-frequency stimulated fasttwitch muscle of rat. Am J Physiol 1999;277:C1122-9.

43. Chin ER, Olson EN, Richardson JA, et al. A calcineurin-dependent transcriptional pathway controls skeletal muscle fiber type. Genes Development 1998;12:2499-509.

44. Green HJ, Düsterhöft S, Dux L, Pette D. Metabolite patterns related to exhaustion, recovery and transformation of chronically stimulated rabbit fast-twitch muscle. Pflügers Arch 1992;420:35966.

45. Hicks A, Ohlendieck K, Göpel SO, Pette D. Early functional and biochemical adaptations to lowfrequency stimulation of rabbit fast-twitch muscle. Am J Physiol 1997;273:C297-305. 


\section{Chronic low-frequency stimulation revisited}

Eur J Transl Myol 2017;27(1):33-39

46. Moerland TS, Wolf NG, Kushmerick MJ. Administration of a creatine analogue induces isomyosin transitions in muscle. Am $\mathrm{J}$ Physiol 1989;257:C810-6.

47. Ren JM, Ohira Y, Holloszy JO, et al. Effects of ßguanidinopropionic acid-feeding on the patterns of myosin isoforms in rat fast-twitch muscle. Pflügers Arch 1995;430:389-93.

48. $\mathrm{Xu} \mathrm{H}, \mathrm{Wu} \mathrm{XR}$, Wewer UM, et al. Murine muscular dystrophy caused by a mutation in the laminin alpha 2 (Lama 2) gene. Nat Genet 1994;8:297-302.

49. Luthert P, Vrbová G, Ward KM. Effects of low frequency electrical stimulation on muscles of dystrophic mice. J Neurol Neurosurg Psychiatry 1980;43:803-9.

50. Dangain J, Vrbová G. Long term effect of low frequency chronic electrical stimulation on the fast hind limb muscles of dystrophic mice. J Neurol Neurosurg Psychiatry 1989;52:1382-9.

51. Reichmann H, Pette D, Vrbová G. Effect of low frequency electrical stimulation on enzyme and isozyme patterns of dystrophic mouse muscle. FEBS Lett 1981;128:55-8.

52. Scott OM, Vrbová G, Hyde SA, et al. Responses of muscles of patients with Duchenne Muscular Dystrophy to chronic electrical stimulation. J Neurol Neurosurg Psychiatry 1986;49:1427-34.

53. Scott OM, Vrbová G, Hyde SA, et al. Therapeutic possibilities of chronic low frequency electrical stimulation in children with Duchenne muscular dystrophy. J Neurol Sci 1990;95:171-82.
54. Putman CT, Sultan KR, Wassmer T, et al. Fibertype transitions and satellite cell activation in lowfrequency-stimulated muscles of young and aging rats. J Gerontol A Biol Sci Med Sci 2001;56:B5109.

55. Nuhr MJ, Pette D, Berger R, et al. Beneficial effects of chronic low-frequency stimulation of thigh muscles in patients with advanced chronic heart failure. Eur Heart J 2004;25:136-43.

56. Stein RB, Chong SL, James KB, et al. Electrical stimulation for therapy and mobility after spinal cord injury. Progr Brain Res 2002;137:27-34.

57. Kern H, Carraro U, Adami N, et al. Home-based functional electrical stimulation rescues permanently denervated muscles in paraplegic patients with complete lower motor neuron lesion. Neurorehabil Neural Repair 2010;24:709-21.

58. Kern H, Salmons S, Mayr W, et al. Recovery of long-term denervated human muscles induced by electrical stimulation. Muscle Nerve 2005;31:98101.

59. Mayr W. Neuromuscular Electrical Stimulation for Mobility Support of Elderly. Eur J Transl Myol 2015;25:263-8.

60. Zampieri S, Mosole S, Löfler S, et al. Physical Exercise in Aging: Nine Weeks of Leg Press or Electrical Stimulation Training in 70 Years Old Sedentary Elderly People. Eur J Transl Myol 2015;25:237-42.

61. Protasi F. Mitochondria Association to Calcium Release Units is Controlled by Age and Muscle Activity. Eur J Transl Myol 2015:257-62. 